\title{
LAS EXPORTACIONES MINERAS, LOS IMPUESTOS DIRECTOS E INDIRECTOS Y SU INCIDENCIA EN LA RECAUDACIÓN TRIBUTARIA DEL GOBIERNO CENTRAL: 2017 -2019
}

\author{
MINING EXPORTS, DIRECT AND INDIRECT TAXES AND THEIR INCIDENCE IN \\ THE TAX COLLECTION OF THE CENTRAL GOVERNMENT: 2017-2019
}

Eduardo Villa MoRocho Universidad Nacional del Callao Lima, Perú Correo electrónico: EduardoVilla@inei.gob.pe

Nicko Alberto Gomero Gonzales Universidad Nacional Mayor de San Marcos Lima, Perú ORCID: http://orcid.org/0000-0002-5642-8298 Correo electrónico: ngomerog@unmsm.edu.pe

Victor Ricardo Masuda Toyofuku Universidad Nacional Mayor de San Marcos Lima, Perú ORCID: http://orcid.org/0000-0001-6767-9466 Correo electrónico: vmasudat@unmsm.edu.pe

\section{RESUMEN}

Objetivo: Determinar cómo las exportaciones de commodities inciden en los ingresos tributarios del Gobierno Central y el tipo de relación que existe entre de los impuestos directos e indirectos. Método: Se aplicó el método descriptivo correlacional, estructurándose una matriz de correlación y líneas de regresión, para ello se empleó datos oficiales de la SUNAT, INEI, BCRP. Resultados: En el estudio se evidencia el mayor aporte del IGV en la recaudación tributaria, seguido del impuesto a la renta, pero por el grado de correlación alcanzado este último impuesto tiene mayor incidencia en la recaudación fiscal. Sin embargo, al contrastar las exportaciones mineras con los impuestos directos se aprecia una débil, pero negativa relación de dependencia lo cual implica que la recaudación tributaria es débilmente afectada por las exportaciones de minerales. Conclusiones: Se concluye, por el grado y tipo de correlación obtenido, que el aumento de las exportaciones mineras no ejerce mayores cambios en la recaudación tributaria siendo además el impacto de tipo inverso.

Palabras clave: Impuestos; renta; exportaciones; recaudación tributaria; minería.

\begin{abstract}
Objective: To relate how commodity exports impact to the tax revenues of the Central Government and the type of relationship that exists between direct and indirect taxes. Method: The type of research is correlational descriptive method was applied, structuring a correlation matrix and regression lines, for that was applied an official data from SUNAT, INEI, BCRP. Results: The study shows the greatest contribution of the IGV in tax collection, followed by income tax, but due to the degree of correlation reached, this last tax has a bigger incidence on tax collection. However, to contrast the mining exports with the direct taxes, it appreciates a weak and negative dependence relationship, in which it implies that the tax collection is weakly affected by the mineral exports. Conclusions: It concludes, by the grade and type of correlation obtained, that the increase in mining exports does not exert bigger changes in tax collection being the inverse type impact.
\end{abstract}

Keywords: Taxes; income; exports; tax collection; mining. 


\section{INTRODUCCIÓN}

Se conoce que la economía en vías de desarrollo centra su avance económico en la exploración, extracción, producción y exportación de productos con mínimo o nulo valor agregado, la ausencia de las franjas industriales, por no poseer los soportes tecnológicos del caso, los induce a alimentar su frente interno con productos exportables como los mineros de alta dependencia a los vaivenes del mercado internacional. Si bien, este tipo de actividad, tiene impacto positivo en la generación de divisas, en el Producto Bruto Interno (PBI), hasta en la solidez tributaria, a largo plazo, los resultados simétricos de bienestar en la sociedad serán marginales.

Para explicar la importancia del sector minero en la economía es importante tomar en cuenta lo señalado por Flores, Quiñones, Baca y De Echave (2017), quienes consideran que:

El aporte del sector minero al PBI ha sido creciente en los últimos quince años, de la mano de las inversiones privadas que llegaron al sector desde inicios de la década de 1990, especialmente durante el súper ciclo de los precios, entre el 2003 y el 2012, cuyo aporte pasó de menos de 5\% a inicios de los años 90 al 10\% en el 2007, para luego ubicarse en 9,7\% en el año 2016. (...). El incremento sostenido de las cotizaciones de los metales en el mercado mundial determinó en el Perú, y en la región, una década de bonanza con inversiones crecientes, utilidades extraordinarias para las empresas e ingresos fiscales importantes para el Estado (p.9).

Las exportaciones de productos tradicionales conocidos como commodities mineros, están marcadas en su comportamiento por los concentrados mineros, como el cobre, el zinc, el oro, la plata, entre otros; que, por sus características propias, sus cotizaciones poseen altas tasas de correlación con el avance de la economía mundial, especialmente de la China y EE. UU. Que, como se sabe, poseen la supremacía económica del mundo. La inestabilidad de los mercados internacionales se traduce en grados de riesgo para el sector exportador de estos tipos de productos, que en ciertos casos vulneran las cuentas macroeconómicas y las fiscales. Este caso es común en países que sustentan su economía en la exportación de productos mineros que, dicho sea de paso, generan escenarios de vulnerabilidad en periodo de crisis global, como lo sucedido por ejemplo en el 2009, año en que se desencadenó una severa contracción de la economía mundial.

La volatilidad de los precios es otra de las características de estos tipos de productos, ya que pueden aumentar o bajar las cotizaciones en el mercado internacional; estos cambios están supeditados a cómo se muevan las dos fuerzas del mercado, que además, al ser caracterizados como inelásticos, este tipo de sensibilidad va a repercutir en las cuentas financieras de las empresas especializadas en la exportación de estos productos, cuyos impactos además llegarán a los ingresos fiscales del gobierno.

El hecho de que una economía esté anclada en forma significativa a la producción y exportación de commodities, va a presentar un elevado riesgo para el PBI, con ello la recaudación tributaria podría aumentar en periodos alcistas de los mercados globales, y sus caídas serán vertiginosas ante recesiones de estos mismos mercados. Como la diversificación está ausente en la estrategia de comercialización, los riesgos son explícitos y de inmediato los efectos perniciosos en los diferentes escenarios económicos y sociales de este tipo de economía, siendo una clara evidencia lo sucedido con la economía peruana, que como bien se sabe, la exportación de minerales ha sido una práctica de exportación histórica que no ha logrado apalancar a la economía a niveles de crecimientos sostenidos, muestra de ello es el PBI per cápita, que según el Instituto Nacional de Estadística e Informática (INEI) está por el orden de los U\$5000, mientras que otros países que sí han desarrollado una plataforma industrial y tecnológica, como por ejemplo Alemania, este indicador macroeconómico al 2018 llego a los 40800 euros.

No hay duda que esta actividad extractiva tiene ciertas bondades, como la tributaria, que según la revista Actualidad Minera (2017) el aporte en materia de impuesto a la renta entre 2012 y 2016 llegó a los S/ 32242 millones, pero si se visualiza en forma integral y a largo plazo los impactos sociales y económicos no son tan alentadores, para evidenciar este hecho, solo basta apreciar las graves deficiencias estructurales que se presentan en el país.

Se estima que uno de los indicadores que se ve vulnerado con la volatilidad de las exportaciones mineras, que como se dijo está influenciado por las cotizaciones de los minerales en el mercado internacional, son los tributos que recauda el Gobierno central, aquellos que se originan por la aplicación del impuesto a la renta, específicamente, el de tercera categoría, cuya incidencia directa recae en las utilidades de las empresas. Se entiende que, en escenarios de robustez de la economía global, las empresas mineras consolidarán sus ingresos por exportación que a la vez aumentarán sus utilidades, lo cual les debe conllevar a pagar más impuestos. Pero en escenarios de recesión global, bajo esta misma lógica, las cuentas tributarias del Gobierno se verán debilitadas, este comportamiento simétrico debería conllevar a estimar una alta correlación entre los ingresos fiscales y la exportación de minerales. 
Mendoza (2011) señala, desde el punto de vista macroeconómico, "un país rico en minerales e hidrocarburos debería buscar, en el largo plazo, maximizar el valor presente neto (VPN) del flujo de ingresos provenientes de la actividad en esos sectores, incluyendo lo que recibe el Estado como impuestos" (p.13). Lo señalado por el analista expresa claramente que un país que produce y exporta minerales, mediante esta actividad, sustenta su frente interno incluyendo aquellos recursos financieros que utiliza el gobierno para solventar sus gastos corrientes y de capital, cuyo impacto multisectorial se debe apreciar en el largo plazo.

De lo señalado se podría inferir que la salud de las empresas exportadoras y con ello la estructura financiera del gobierno, basados en los impuestos que recauda va a estar supeditada a los avances económicos de los principales países importadores, especialmente de la China , que por sus tasas de crecimiento sostenido debe de acudir al mercado internacional de materias primas para demandar estos tipos de productos, tal como el cobre, que como se conoce es el principal demandante en el mundo.

Por el esbozo teórico realizado, se puede plantear como hipótesis que la recaudación tributaria va a responder directamente a las exportaciones mineras, cuyo performance estará anclado a los vaivenes del mercado internacional. Los impactos no solo deberían centrarse en los impuestos cuya incidencia directa recae sobre las utilidades de las empresas, sino que además otro impuesto que se verá afectado será el Impuesto General a las Ventas (IGV), ya que el dinamismo de las exportaciones debe empujar a la demanda agregada en la misma dirección vía el consumo privado, si bien este último grado de dependencia es menos directo, no deja de comportase como una fuente importante de generación de recursos financieros para el gobierno, por lo que debe suponerse que las exportaciones debe mostrar una correlación directa con los impuestos con la producción y el consumo.

El argumento del Instituto Peruano de Economía (2011) corrobora lo especificado en la hipótesis, puesto que, este centro de investigación llega a determinar que aparte que el comportamiento cíclico de la recaudación tributaria es afectado por los precios de los minerales, también llega a estimar que la producción es otra variable relevante en su formación, el cual está supeditada a los niveles de inversión.

Bajo el contexto señalado, el objetivo del artículo se centra en explicar cómo las exportaciones de minerales o concentrados de las empresas nacionales inciden en los flujos tributarios del Gobierno central dándole con ello un cierto grado de sostenibilidad. Hay que tener en cuenta que la robustez tributaria del Gobierno central no solo está influenciada por los impuestos empresariales conocidos como rentas de tercera categoría, sino que sumado a estos existen otras fuentes impositivas que deben ser monitoreadas para evaluar la eficacia de su impacto, entre estos están el impuesto a la renta de cuarta y quinta categoría que se aplican a las rentas del trabajo que en cierta forma se constituyen en importantes fuentes de ingresos financieros para el gobierno.

Lo afirmado encuentra solidez cuando Flores et al. (2017) refieren que:

El esquema tributario definido a inicios de los años 90 para el sector minero estaba compuesto principalmente por el impuesto a la renta y un conjunto de exoneraciones y beneficios tributarios orientados a incentivar las inversiones privadas. Dicho esquema permaneció sin cambios sustantivos hasta el año 2011, puesto que las regalías mineras aprobadas en el año 2004 tuvieron una aplicación parcial, porque las principales empresas estaban protegidas por contratos de estabilidad jurídica. El incremento en las cotizaciones de los minerales de inicios del siglo XXI tuvo un efecto directo en las utilidades de las empresas $y$, por consiguiente, en los ingresos fiscales, principalmente en el impuesto sobre la renta. Los tributos internos y, en particular, el impuesto a la renta son los principales indicadores para medir el aporte de la minería a los ingresos fiscales (p.10).

Del Valle (2013) señala que:

La importancia de los recursos naturales en Perú no radica solo en los volumenes de producción, sino en los ingresos que estos sectores generan para el fisco a través de impuestos y rentas especiales por uso de la propiedad del Estado: las regalías (p.7).

El autor enfoca su análisis solo en el tema tributario, pero para medir oportunidades que genera este sector debe ir más allá del campo financiero gubernamental, si fuera así, se estaría dejando de lado los temas ambientales y sociales que trae consigo esta actividad productiva.

Por último, cabe precisar lo señalado por Guj (2012) quien dice:

Los impuestos especiales para el sector minero, incluyendo las regalías mineras tradicionales, en combinación con las disposiciones estándares o específicas de la minería para el impuesto a los ingresos corporativos, son los principales componentes de un régimen fiscal minero que puede ser usado para lograr el balance deseado de un número de objetivos gubernamentales fundamentales (p.5). 


\section{MATERIALES Y MÉTODO}

La investigación es de tipo descriptivo y correlacional, donde se analizó el grado y tipo de relación entre las exportaciones mineras y la recaudación tributaria, para ello se empleó como instrumento estadístico el coeficiente de correlación de Pearson, además se determinó la ecuación de regresión lineal para las variables bajo análisis. Para determinar estos datos estadísticos se utilizó información secundaria obtenida de fuentes oficiales, como el INEI, BCRP, SUNAT, lo cual dará confiabilidad a los resultados obtenidos. Para el desarrollo de la investigación se siguió todo el proceso investigativo, desde la formulación del problema con el planteamiento teórico, el cual se plasmó en la introducción, que sirvió como fundamento para procesar la información estadística y llegar a resultados y aportes sobre aspectos tributarios, que fue materia de investigación.

\section{RESULTADOS}

A continuación, se presentan los diversos tipos de impuestos que son aplicados por el Gobierno central con fines recaudatorios, que como se conoce, alimentan sus cuentas fiscales mayormente con dos tipos de impuestos, directo (impuesto a la renta) y los indirectos conocido como el IGV, con una presión tributaria del 8,2\% y del 5,6\% en el 2018, respectivamente. En términos monetarios el IGV llega en promedio mensual a los 8 mil millones en contra de los 3,4 millones de soles del impuesto a la renta por mes. Estos dos tipos de impuestos representan como promedio el $65 \%$ de lo que el gobierno utiliza para financiar sus gastos operativos y de inversiones. Cabe señalar que, el impuesto a la renta está supeditada a los niveles de ingresos que obtienen los sujetos tributarios y en cuanto al IGV va a depender de la capacidad de gasto de los consumidores; por ello, cuando la economía experimenta crecimientos sostenidos, los ingresos tributarios tienen el mismo comportamiento, evidenciando este hecho en su alta correlación. Las cifras de recaudación de impuestos se pueden apreciar en la tabla 1, la cual destaca la recaudación por aplicación del IGV que en promedio en el 2017 llegó a los 55,5 mil millones de soles. Básicamente los ingresos tributarios, que en el 2017 y 2018 ascendieron a 90.7 mil millones de soles y 104.8 mil millones de soles fueron sustentados por el IGV y el impuesto a la renta, respectivamente.

La correlación entre el IGV y el impuesto a la renta es del R: $13,9 \%$, por la cifra encontrada se puede decir que existe una débil relación entre estos dos tipos de impuestos, pero se evidencia que se desplazan en la misma dirección, que en parte es recomendable para el Gobierno, ya que, ante un posible choque adverso de los mercados, los impactos no serían significativos en los impuestos señalados; por lo tanto los ingresos tributarios por este lado no se verían significativamente vulnerados. Si bien se podría contraer los impuestos empresariales, pero no se comprometería en forma significativa el impuesto a la producción y consumo.

Por otro lado, también se evidencia que el impuesto a la renta tiene mayor grado de volatilidad que el IGV, el cual presenta menor oscilación en su recorrido recaudatorio, las cifras señalan que la desviación típica para ambos impuestos es de 1211 soles y 461, respectivamente. Estos últimos resultados en parte se explican por la alta volatilidad de la economía global y del escenario interno, que impacta negativamente en las utilidades que reciben los sujetos tributarios, como es el caso a los impuestos de renta de tercera categoría que tiene que ser pagado por las empresas. Estos resultados se muestran en la Figura 1. Cabe precisar que la recaudación por impuesto a la renta solo está por encima del IGV en el mes de abril, periodo en el cual los sujetos tributarios tienen que declarar y pagar este tipo de impuestos. En los demás meses, el IGV supera en recaudación al Impuesto a la Renta (IR), por ello se afirma que es el tipo de impuesto que le genera mayores rentas permanentes al Gobierno Central.

El comportamiento del IGV y del Impuesto Selectivo al Consumo (ISC) en el periodo analizado es el reflejo de lo que ha sido históricamente el comportamiento de estos dos tipos de impuesto; el primero de estos con mayor estabilidad en la recaudación, el cual quedó evidenciado por su menor desviación típica y, asimismo, por su mayor monto recaudado, por ello la presión tributaria de este impuesto es el más representativo dentro de los instrumentos recaudatorios del gobierno.

Si bien, el IGV posee mayor robustez en los ingresos tributarios, al revisar las cifras de correlación entre estos tipos de impuestos y los ingresos tributarios se puede apreciar que el impuesto a la renta presenta mayor correlación, lo cual significa que la recaudación tributaria es más sensible a los cambios del impuesto a la renta, como se aprecia en la tabla 2, el coeficiente de correlación llega al $88,8 \%$, por lo que las autoridades fiscales deben de esperar que las empresas y personas naturales que asumen este compromiso ejercerán mayor presión en los cambios en ingresos tributarios en comparación con el IGV cuya correlación es del R : 48\%, lo cual se puede calificar como moderado.

Según información empírica, se atribuye a las exportaciones mineras una alta ponderación a los ingresos tributarios que recibe el Gobierno central, ya que es de esperar que con los vaivenes de los precios de las materias primas en el mercado internacional las empresas dedicadas a este tipo de actividad mejoren sus utilidades, y con ello, aumente su base imponible, lo cual debe traducirse con 
Tabla 1

Impuestos directos e indirectos y exportaciones (Millones de S/) *2017-2019.

\begin{tabular}{|c|c|c|c|c|c|}
\hline $2017 / 2018$ & $\begin{array}{c}\text { Impuesto de tercera } \\
\text { Categoría }\end{array}$ & $\begin{array}{l}\text { Ingresos } \\
\text { Tributarios }\end{array}$ & Impuesto a la Renta & $\begin{array}{c}\text { Exportaciones } \\
\text { Mineras }\end{array}$ & $\begin{array}{c}\text { Impuesto General } \\
\text { a las Ventas }\end{array}$ \\
\hline \multicolumn{6}{|l|}{2017} \\
\hline Enero & 1827,1 & 7929,70 & 3696,50 & 5961,9 & 5132,9 \\
\hline Febrero & 1692,1 & 6382,90 & 2847,50 & 7165,5 & 4189,3 \\
\hline Marzo & 1680,1 & 7864,30 & 4164,80 & 6485,6 & 4234,1 \\
\hline Abril & 860,4 & 8796,70 & 4470,40 & 6288,1 & 4129,1 \\
\hline Mayo & 911,8 & 6660,40 & 2386,30 & 7138,4 & 4419,1 \\
\hline Junio & 1029,6 & 6391,90 & 2270,20 & 7705,9 & 4215,5 \\
\hline Julio & 1114,3 & 6675,40 & 2461,90 & 6059,4 & 4584,2 \\
\hline Agosto & 1137,5 & 7461,80 & 2483,00 & 7959,4 & 4764,3 \\
\hline Setiembre & 1175,3 & 7153,80 & 2440,00 & 9461,8 & 4477 \\
\hline Octubre & 1314,4 & 7842,60 & 2741,20 & 7942,2 & 4838,8 \\
\hline Noviembre & 1341 & 7796,00 & 2875,00 & 8572,4 & 4815,7 \\
\hline $\begin{array}{l}\text { Diciembre } \\
2018\end{array}$ & 1415,6 & 9750,10 & 3918,70 & 9146,8 & 4842,9 \\
\hline Enero & 1784,40 & 9173,90 & 3929,00 & 7915,3 & 5518 \\
\hline Febrero & 1758,80 & 7 091,40 & 3160,00 & 7411,0 & 4596,3 \\
\hline Marzo & 1664,50 & 9199,20 & 4723,00 & 8539,8 & 4587,9 \\
\hline Abril & 1164,60 & 12409,20 & 6859,80 & 7693,0 & 4968 \\
\hline Mayo & 1140,60 & 8200,70 & 2765,90 & 8214,5 & 5077,4 \\
\hline Junio & 1337,70 & 8193,00 & 2729,70 & 8691,0 & 4955,4 \\
\hline Julio & 1358,40 & 7986,70 & 2873,70 & 7481,4 & 5185,8 \\
\hline Agosto & 1341,10 & 8108,70 & 2759,30 & 7304,9 & 4949,2 \\
\hline Setiembre & 1330,70 & 8279,80 & 2738,30 & 7230,1 & 5049,5 \\
\hline Octubre & 1394,60 & 8433,30 & 2881,30 & 7450,4 & 5348 \\
\hline Noviembre & 1422,70 & 8606,90 & 2872,20 & 8615,6 & 5261,7 \\
\hline $\begin{array}{l}\text { Diciembre } \\
2019\end{array}$ & 1569,70 & 8906,90 & 3305,90 & 8440,3 & 5169,1 \\
\hline Enero & 1932,20 & 10299.00 & 4119,60 & 7286,6 & 6277,1 \\
\hline Febrero & 1785,50 & 8043.80 & 3134,30 & 6 610,8 & 4947,3 \\
\hline Marzo & 1793,10 & 9310.70 & 5 012,40 & 6984,7 & 4643,2 \\
\hline Abril & 1184,90 & 12984.10 & 6857,20 & 7511,0 & 5144,4 \\
\hline
\end{tabular}

Fuente: Superintendencia Nacional de Aduanas y de Administración Tributaria (SUNAT).

*Se tomó en cuenta el tipo de cambio promedio del mes del año correspondiente para convertir dólares a soles.

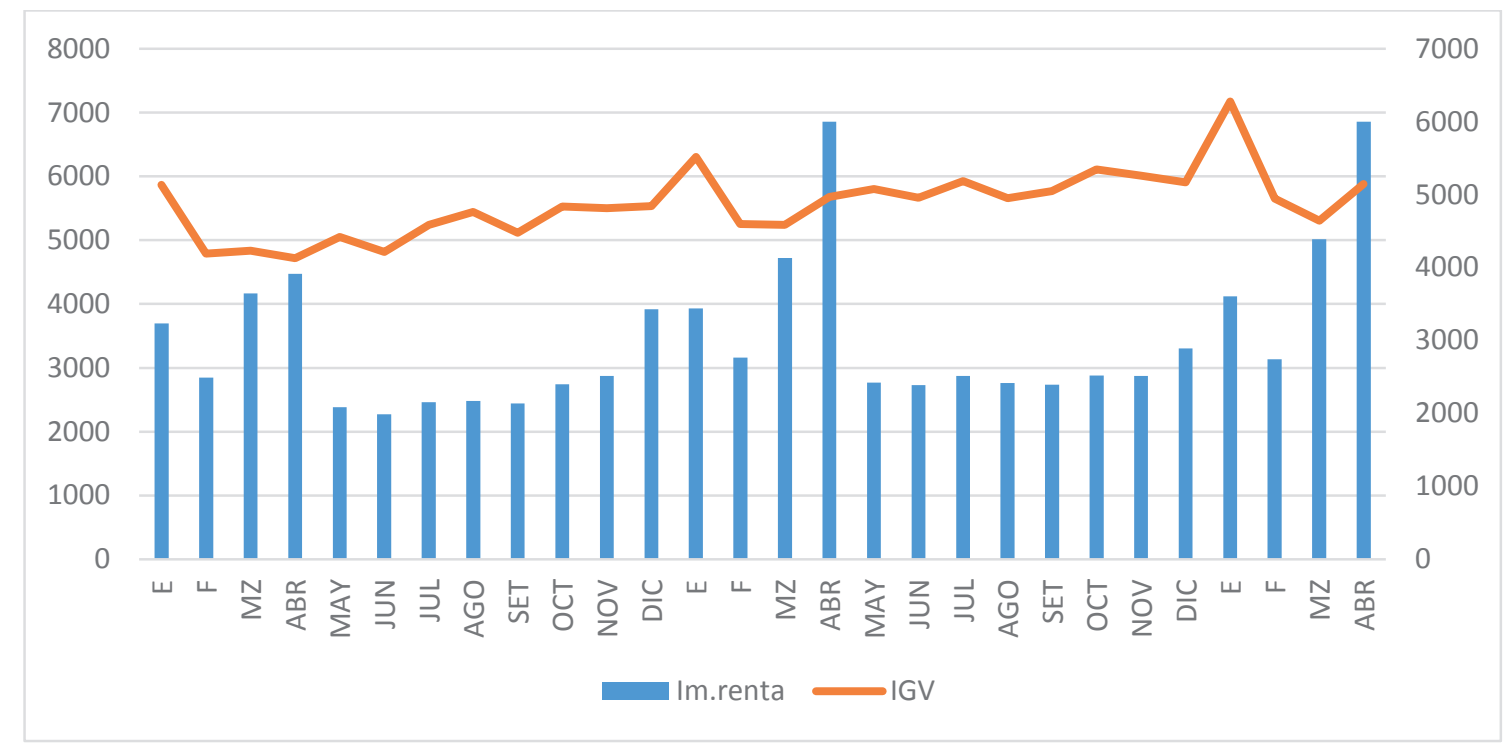

Figura 1. Impuesto a la renta y el Impuesto General a las Ventas en miles de Soles (2017-2019).

Fuente: Elaboración propia con datos del BCRP. 
Tabla 2

Matriz de correlación. Impuestos directos e indirectos.

\begin{tabular}{|c|c|c|c|c|c|c|}
\hline \multicolumn{7}{|c|}{ Correlaciones } \\
\hline & & $\begin{array}{l}\text { Impuesto de tercera } \\
\text { Categoría }\end{array}$ & $\begin{array}{l}\text { Ingresos } \\
\text { Tributarios }\end{array}$ & $\begin{array}{l}\text { Impuesto a la } \\
\text { Renta }\end{array}$ & $\begin{array}{c}\text { Exportaciones } \\
\text { Mineras }\end{array}$ & $\begin{array}{l}\text { Impuesto } \\
\text { General a } \\
\text { las Ventas }\end{array}$ \\
\hline \multirow{3}{*}{$\begin{array}{c}\text { Impuesto de tercera } \\
\text { Categoría }\end{array}$} & Correlación de Pearson & 1 & 0,088 & 0,147 & $-0,124$ & $0,395^{*}$ \\
\hline & Sig. (bilateral) & & 0,655 & 0,455 & 0,528 & 0,038 \\
\hline & $\mathrm{N}$ & 28 & 28 & 28 & 28 & 28 \\
\hline \multirow{3}{*}{ Ingresos Tributarios } & Correlación de Pearson & 0,088 & 1 & $0,888^{* *}$ & 0,120 & $0,479^{* *}$ \\
\hline & Sig. (bilateral) & 0,655 & & 0,000 & 0,544 & 0,010 \\
\hline & $\mathrm{N}$ & 28 & 28 & 28 & 28 & 28 \\
\hline \multirow{3}{*}{ Impuesto a la Renta } & Correlación de Pearson & 0,147 & $0,888^{* *}$ & 1 & $-0,118$ & 0,139 \\
\hline & Sig. (bilateral) & 0,455 & 0,000 & & 0,550 & 0,480 \\
\hline & $\mathrm{N}$ & 28 & 28 & 28 & 28 & 28 \\
\hline \multirow{3}{*}{$\begin{array}{c}\text { Exportaciones } \\
\text { Mineras }\end{array}$} & Correlación de Pearson & $-0,124$ & 0,120 & $-0,118$ & 1 & 0,137 \\
\hline & Sig. (bilateral) & 0,528 & 0,544 & 0,550 & & 0,488 \\
\hline & $\mathrm{N}$ & 28 & 28 & 28 & 28 & 28 \\
\hline \multirow{3}{*}{$\begin{array}{c}\text { Impuesto General a } \\
\text { las Ventas }\end{array}$} & Correlación de Pearson & $0,395^{*}$ & $0,479^{* *}$ & 0,139 & 0,137 & 1 \\
\hline & Sig. (bilateral) & 0,038 & 0,010 & 0,480 & 0,488 & \\
\hline & $\mathrm{N}$ & 28 & 28 & 28 & 28 & 28 \\
\hline
\end{tabular}

*. La correlación es significativa en el nivel 0,05 (bilateral).

**. La correlación es significativa en el nivel 0,01 (bilateral).

Fuente: Elaboración propia.

un mayor pago de impuestos, lo cual implica que debe existir una correlación que refleje una causalidad directa entre estas variables, por lo que al contrastar las cifras de las exportaciones mineras con los ingresos tributarios llega al 12\%, cifra que si bien refleja una baja correlación evidencia que a medida que mejora el mercado mundial de commodities, el Gobierno central debe esperar un aumento en la recaudación tributaria. Si bien la contribución monetaria de la actividad minera al Estado es importante y que además posee una alta cuota de participación en los impuestos directos, como es el caso del impuesto a la renta, no se aprecia una estrecha relación de causalidad en su comportamiento histórico. Este tipo de relación se puede apreciar en la figura 2 , en donde el recorrido de la actividad minera tiene una leve simetría con los componentes tributarios, ingresos que muestran independencia en su recorrido.

Situación distinta se observa cuando se contrasta el impuesto de tercera categoría, que es el que se aplica a las utilidades empresariales, con las exportaciones mineras, cuya correlación es de $\mathrm{R}=-12,4 \%$, cifra que denota que los impuestos de este tipo tienen un recorrido inverso a las exportaciones mineras, lo cual implica que un aumento en las exportaciones de concentrados mineros no se han de traducir en mayores ingresos por la aplicación de impuestos de tercera categoría. Este resultado denota que las utilidades de las empresas mineras, base imponible en donde recae los impuestos, no ha experimentado mejora alguna con el aumento de las exportaciones de concentrados; todo lo contrario, el coeficiente de correlación podría estar indicando, que si bien los ingresos de las empresas pudieran haber mejorado, los costos operativos o financieros han podido aumentar más que proporcionalmente anulando este tipo de ventaja, hecho que podría sustentar el tipo de coeficiente de correlación, la cual es baja pero negativa, caso que se evidencia en la figura 3, en donde el coeficiente de determinación R2: 0,0002 explica que las exportaciones solo explican la formación del impuesto a la renta de tercera categoría en un 0,02\%.

El mismo comportamiento se presenta cuando se contrasta el impuesto a la renta con las exportaciones mineras, obteniéndose un coeficiente de correlación R: -11,8\%, resultado que evidencia que una mejora de las exportaciones no tendrá el mismo impacto en el impuesto a la renta. Cabe precisar que el hecho que la correlación entre los impuestos directos y los ingresos tributarios llega al 88,8\%, es una señal que este tipo de ingresos que recibe el Gobierno central está sustentado por otros tipos de actividades, como el comercio, servicios, ingresos de los trabajadores independientes y dependientes, pero no tanto así, por los 


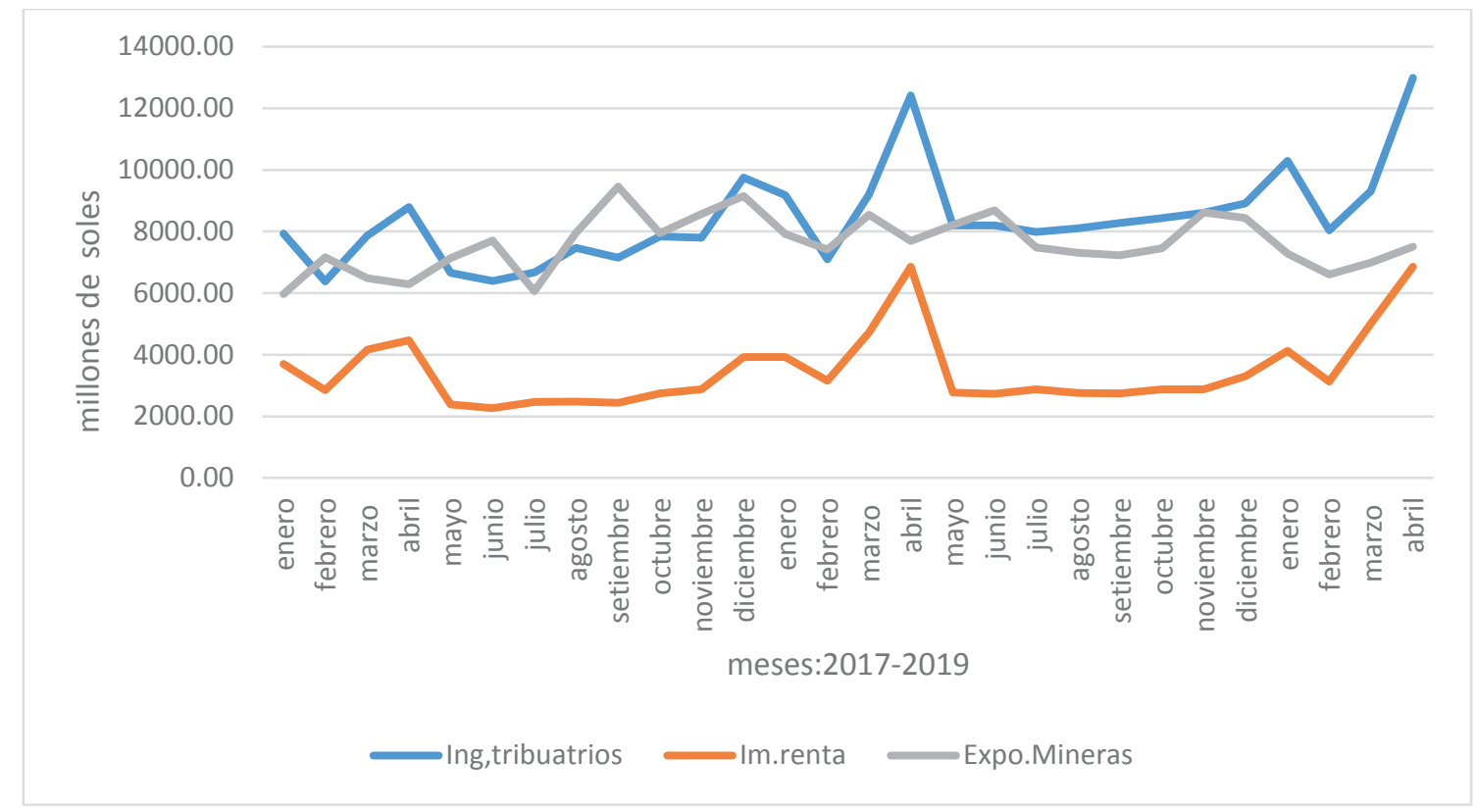

Figura 2. Impuesto a la renta, exportaciones e ingresos tributarios: 2017-2019. (millones de soles). Fuente: Elaboración propia con datos del INEI.

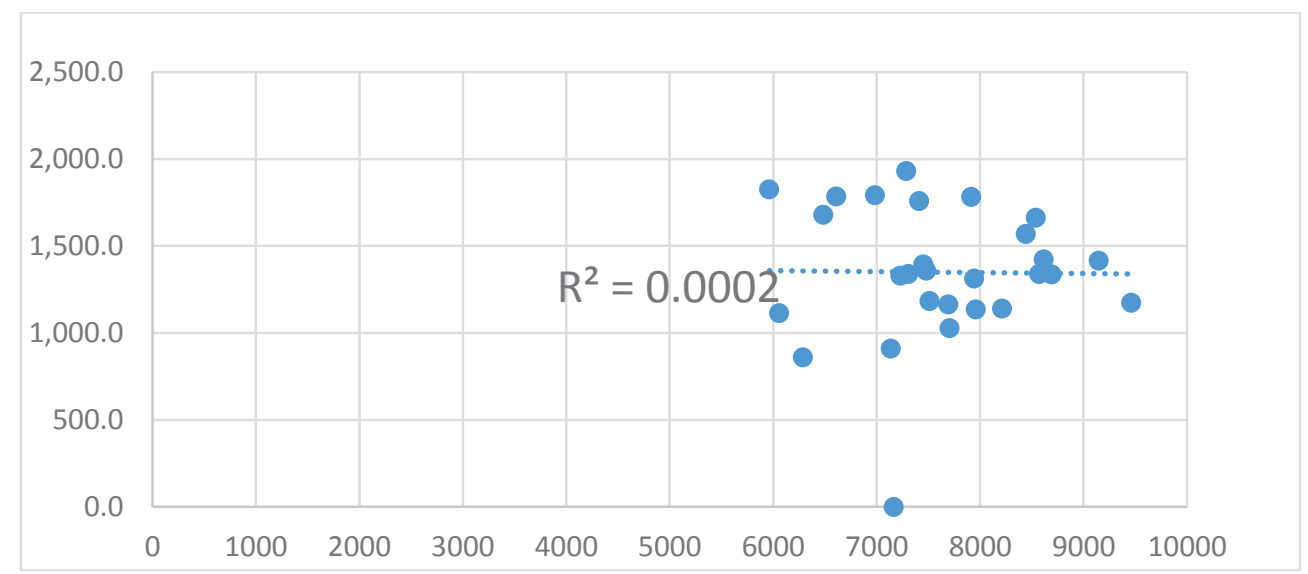

Figura 3. Exportaciones mineras en impuestos a la renta de tercera categoría: 2017-2018.

Fuente: Elaboración propia con datos de SUNAT.

que se deriven de la industria minera. Como ya se señaló, en el periodo bajo análisis los ingresos tributarios mostraron mayor sensibilidad al impuesto a la renta en comparación con el IGV, que como quedó señalado en la matriz de correlación el coeficiente R fue del 47,9\%, el cual se puede calificar como una relación moderada. Esta débil correlación entre el impuesto a la renta y las exportaciones mineras se complementa con el coeficiente de determinación que llega al $\mathrm{R}^{2}$ 0,0143, indicando que las exportaciones solo explican el $1,43 \%$ de la formación del impuesto a la renta; en un $98,57 \%$ es explicada por otros factores, mejor dicho, sujetos tributarios que operan en distintos sectores económicos. Resultado que se aprecia en la figura 4.

Caso distinto sucede cuando se contrasta los ingresos tributarios por la aplicación del IGV con las exportaciones mineras, cuyo coeficiente de correlación del R: 13,7 \% se puede calificar como baja, pero como es positiva, implica que a medida que mejoren este tipo de exportaciones, la recaudación del IGV tendrá el mismo comportamiento, que si bien el impacto no será significativa, pero sí evidencia que el consumidor tendrá mayor propensión a gastar en el mercado interno ante un cambio positivo de las exportaciones 
de commodities mineros. Este resultado positivo se puede explicar por el lado de la demanda agregada interna, componente del PBI que debe mejorar con las exportaciones, que por las cifras del INEI representa en promedio el 75\% del total de exportaciones. Como el mayor dinamismo del mercado internacional implicará un cambio en el consumo privado, automáticamente con ello debe mejorar la recaudación por la aplicación del IGV, que por cierto el tipo de relación está muy alejada de la perfecta simetría. El $\mathrm{R}^{2}$ está señalando que la formación del IGV o recaudación del mismo, se explica en un $1.87 \%$ por las exportaciones mineras (ver figura 5).
Si bien el IGV, por el monto recaudado, es el tipo de impuesto que más contribuye a los ingresos tributarios del Gobierno central determina la regresión lineal simple (RLS) lo cual evidencia que este impuesto explica solo el 22,91\% de los ingresos fiscales, tal como se aprecia en la figura 6, por lo que hay otros tipos de impuestos como el de la renta que ejerce mayor impacto en su comportamiento, situación que se corrobora con el mayor coeficiente de determinación que llega al $\mathrm{R}^{2}: 94,2 \%$. Cabe precisar que este resultado no está sustentado básicamente por las exportaciones mineras, sino por otras actividades económicas que están afectas a este tipo de impuestos. (ver figura 6).

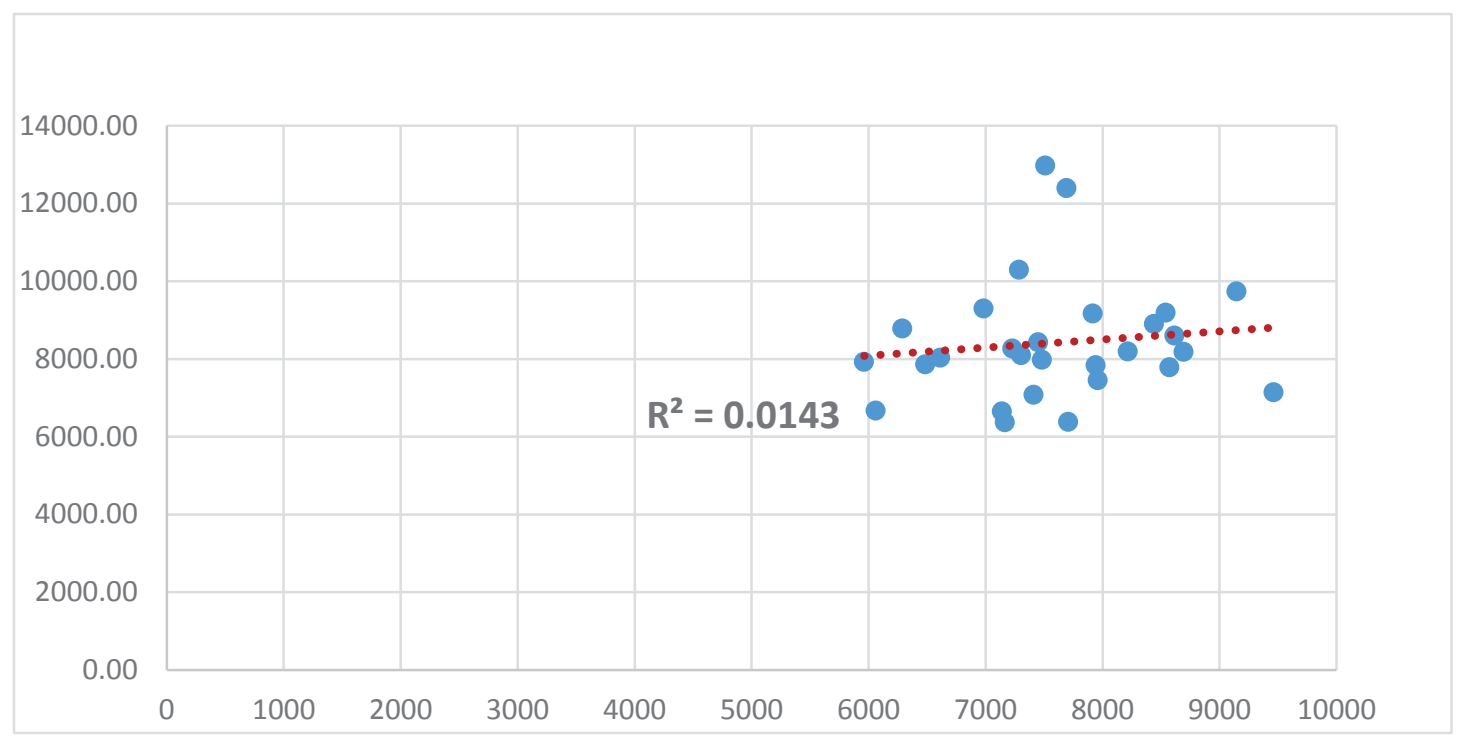

Figura 4. Exportaciones mineras e ingresos tributarios: 2017-2018.

Fuente: Elaboración propia con datos de SUNAT.

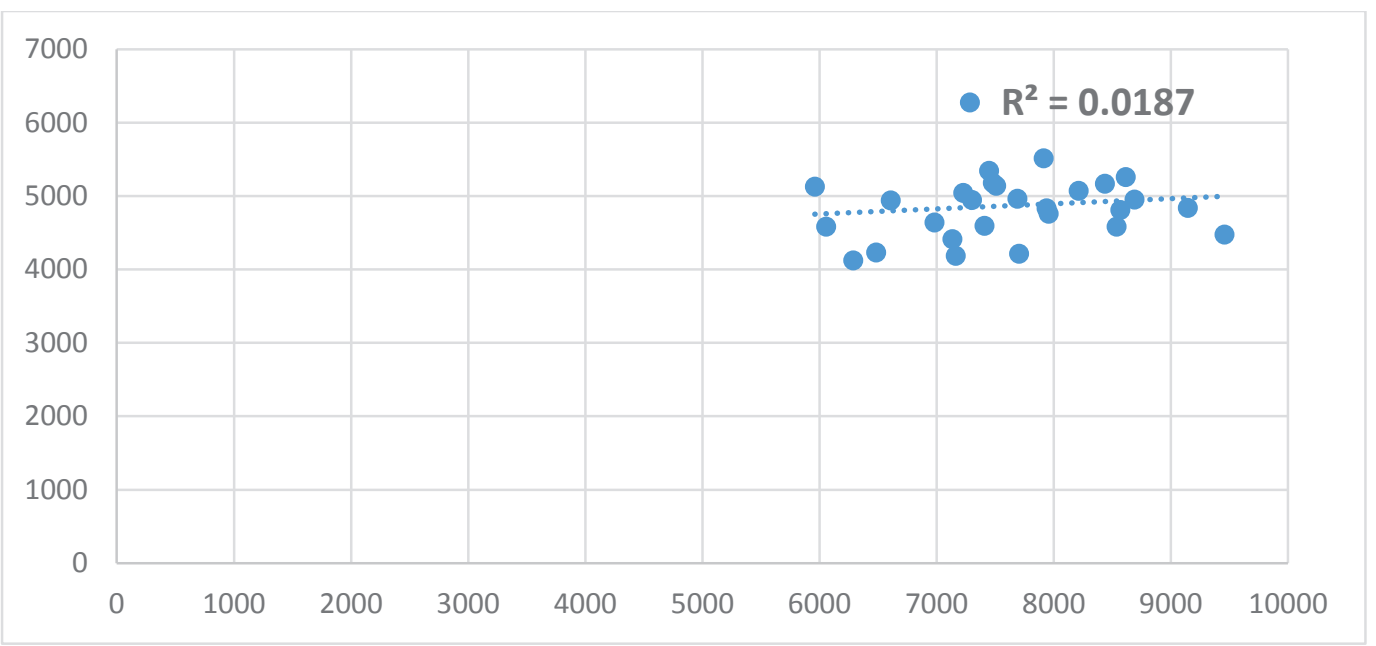

Figura 5. Exportaciones e Impuesto General a las Ventas: 2017-2019.

Fuente: Elaboración propia con datos de SUNAT. 


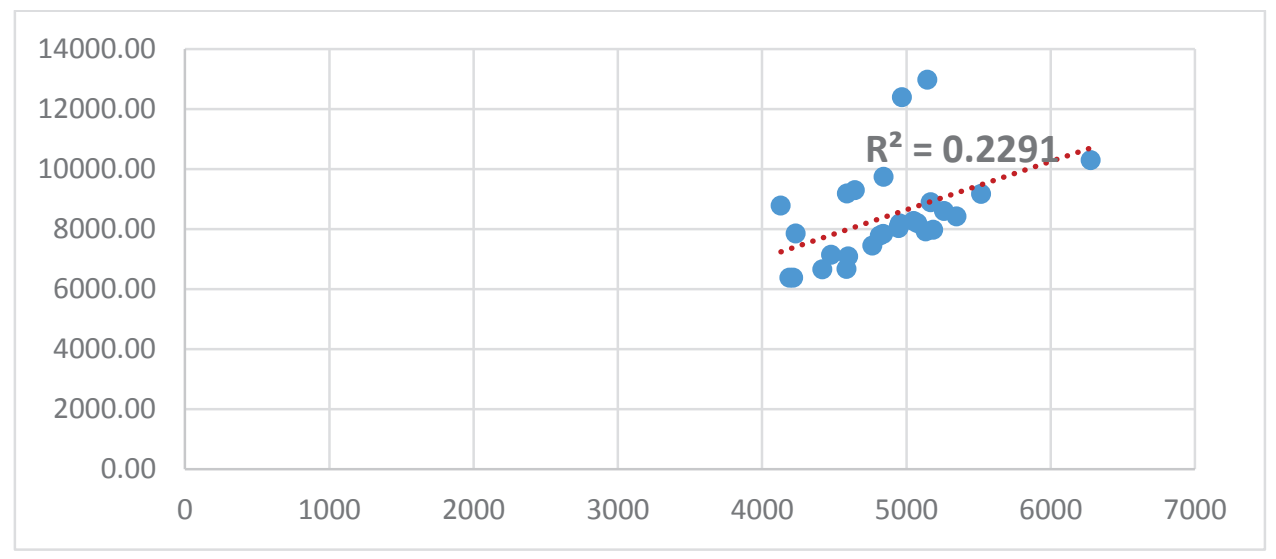

Figura 6. Impuesto General a las Ventas e ingresos tributarios: 2017-2019.

Fuente: Elaboración propia con datos de SUNAT.

\section{DISCUSIÓN}

El impuesto a la venta (IGV) tiene mayor participación en la recaudación tributaria, seguida del impuesto a la renta, cuyo aporte en forma conjunta llegan al 65\% de los ingresos fiscales del Gobierno central. La correlación positiva entre estos dos tipos impuestos y la recaudación tributaria denotan que la recaudación fiscal estará anclada a estos dos tipos de impuestos, pero en mayor grado al impuesto a la renta ya que el grado de correlación llega al $88,8 \%$ en comparación con el IGV que llega al $47,9 \%$. Los ingresos tributarios muestran una débil relación con las exportaciones mineras, resultado que se refleja en el coeficiente de correlación el cual llega al 12,0\%; por lo que se estima que un mayor dinamismo de las exportaciones de este tipo de commodities tendrá un débil impacto en la recaudación tributaria del Gobierno central, situación que se corrobora con el R2 el cual llega al 1,43\%, señalando que las exportaciones mineras explican solo en este porcentaje los ingresos tributarios, el cual se puede calificar como marginal. Los impuestos que se derivan de las utilidades empresariales, específicamente, los de tercera categoría, su grado se incidencia en la recaudación tributaria es débil y a la vez negativa, lo que implica que las utilidades de las empresas mineras no están influenciadas por la exportación de commodities mineros, lo cual explica la débil y negativa correlación entre este tipo de impuestos y las exportaciones de productos mineros. Por lo que cabe esperar que una mayor dinámica exportadora no tendría mayores impactos en las utilidades de las empresas exportadoras de este sector lo cual no conllevaría a mayores cambios en la recaudación de ingresos fiscales. Este mismo caso se presenta cuando se contrasta este tipo de exportaciones y el impuesto a la renta, cuyo coeficiente de correlación y determinación es de R: -11,8\% y R2 :1,39\%, cifras que evidencian débil sensibilidad del impuesto a la renta a las exportaciones de minerales. El IGV muestra mayor dependencia a las exportaciones en comparación con el impuesto a la renta, el coeficiente de correlación es de R: 13,7\%, sustentado básicamente por los cambios en la demanda agregada. La recaudación tributaria por este tipo de impuesto (IGV) es explicada en un $\mathrm{R}^{2}: 1,8 \%$, cifra que proyecta una débil influencia del impuesto que paga el consumidor por las operaciones propias del mercado, en los ingresos fiscales del Gobierno central. Se concluye, además, que el impuesto a la renta, en comparación con otros impuestos, explica en mayor porcentaje a la formación de los ingresos tributarios cuyo $\mathrm{R}^{2}$ es del 78,99\%. Los cambios de los ingresos tributarios debido a las exportaciones, los cuales se llevaron al plano estadístico para determinar el grado de impacto, se ajusta en cierto modo a lo señalado por el Instituto Peruano de Economía (2011), donde el comportamiento cíclico de la recaudación tributaria se ajusta a los vaivenes de los precios internacionales, cuyo comportamiento además se verá reflejado en las utilidades de las empresas mineras. Del mismo modo, es importante contrastar lo encontrado en el trabajo de investigación con lo señalado por Del Valle (2013), quien argumenta que la recaudación tributaria no solo es afectada por los precios de los commodities mineros, sino también por la producción. Los tipos y grados de correlación señalan la forma como los mercados internacionales ejercen sobre los ingresos que obtiene el Gobierno central por la aplicación de los impuestos directos, como es el de la renta y el IGV.

\section{REFERENCIAS BIBLIOGRÁFICAS}

Actualidad Minera (2017): Veinte años de actualidad minera en el Perú. Lima: Cooper Acción. N²18. WWW. coorganizacion.org.pe 
Del valle, M. (2013). Ingresos Fiscales por Explotación de Recursos Mineros e Hidrocarburos en Perú. Banco Interamericano de Desarrollo. Obtenido de: https://publications.iadb.org/es/publicacion/13198/ ingresos-fiscales-por-explotacion-de-recursos-mineros-e-hidrocarburos-en-peru

Flores, C., Quiñones, C., Baca, E. \& De Echave, J. (2017). Recaudación fiscal y beneficios tributarios en el sector minero. Lima: Tarea Asociación Gráfica Educativa. Obtenido de: http://cooperaccion.org.pe/wp-content/ uploads/2017/11/Recaudaci\%C3\%B3n-fiscal-y-beneficios-tributarios-en-el-sector-minero-a-la-luz-delos-casos-Las-Bambas-y-Cerro-Verde-1.pdf

Flores, C., Quiñonez, C., Baca, E., De Ecaheve, J. (2017). Recaudación Tributaria y Recaudación Fiscal y benefi- cios Tributarios: a la luz de los casos Las Bambas y Cerro Verde. Lima: Cooper Acción Perú.

Guj, P. (2012). Regalías mineras y otros impuestos especificos a la minería. Perth: Centro Internacional de Minería para el Desarrollo.

Instituto Peruano de Economía (2011). La tributación minera en el Perú: contribución a la carga tributaria y fundamentos conceptuales: luz de los casantasos de Bambas y Cerro Verde. Lima: Instituto Peruano de Economía.

Mendoza, W. (2011). La política impositiva aplicable a los minerales y al petróleo: teoría, experiencias y propuesta de política para el Perú. Lima: Consorcio de Investigación Económica y Social. 